Check for updates

Cite this: RSC Adv., 2020, 10, 29528

\title{
Rapid characterization of chemical constituents of Shaoyao Gancao decoction using UHPLC coupled with Fourier transform ion cyclotron resonance mass spectrometry $\dagger$
}

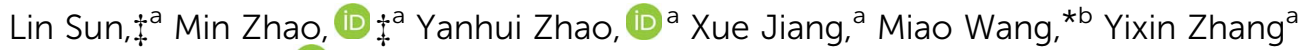
and Chunjie Zhao (iD *a

Shaoyao Gancao decoction (SGD), a well-known Chinese herbal formula, has been used to treat liver injury for a long time. In this study, chemical profiles of SGD were identified using ultra high-performance liquid chromatography combined with Fourier transform ion cyclotron resonance mass spectrometry (UHPLCFT-ICR-MS/MS). Liquid chromatography was performed on a $C_{18}$ column (150 mm $\left.\times 2.1 \mathrm{~mm}, 1.8 \mu \mathrm{m}\right)$; the mobile phase comprised $0.1 \%$ formic acid (A) and acetonitrile (B). We then characterized 73 chemical compounds; the primary constituents in SGD included phenols and monoterpenes (in Paeoniae Radix Alba), triterpene saponins, and flavonoids (in Glycyrrhizae Radix et Rhizoma Praeparata Cum Melle). Thus, this study provides a basis for further study on SGD and is expected to be useful for rapidly characterizing constituents in other traditional Chinese herbal formulations.
\end{abstract}

Received 28th May 2020

Accepted 25th July 2020

DOI: 10.1039/d0ra04701e

rsc.li/rsc-advances

extensively used for treating febrile diseases such as relief of nourishing liver, relaxing spasm, and relieving pain. ${ }^{4}$

At present, few studies have focused on the chemical components of SGD. ${ }^{5}$ To improve the detection range and sensitivity of previous method, researchers are increasingly using UHPLC-FT-ICR-MS, which is a type of powerful qualitative screening platform with a high mass resolving power that demonstrates powerful separation and can generate accurate molecular measurements. For example, using this method, Wang et al. characterized 33 chemical compounds in Cortex Fraxini and Guan et al. characterized 120 chemical compounds in Sijunzi decoction. ${ }^{6,7}$

In our work, we selected UHPLC-FT-ICR-MS to systematically characterize the chemical profiles of SGD. This study is thus able to provide a substantial base and provide considerable information for SGD-related pharmacological research. will then act as the basis for TCM's pharmacology research and clinical applications.

Initially, Shaoyao Gancao decoction (SGD) was described in Shang Han Lun, a clinical TCM book written by Zhang Zhongjing in the Eastern Han Dynasty. ${ }^{3}$ It contains two herbs: Paeoniae Radix Alba and Glycyrrhizae Radix et Rhizoma Praeparata Cum Melle. The SGD was a classical formula of TCM and

\footnotetext{
${ }^{a}$ School of Pharmacy, Shenyang Pharmaceutical University, Wenhua Road 103, Shenyang, Liaoning Province, China. E-mail: lab433@163.com

${ }^{b}$ School of Life Science and Biopharmaceutics, Shenyang Pharmaceutical University, Wenhua Road 103, Shenyang, Liaoning Province, China

$\dagger$ Electronic supplementary information (ESI) available. See DOI: 10.1039/d0ra04701e

‡ Co-first authors.
}

\section{Materials and methods}

\subsection{Chemicals and materials}

Paeoniae Radix Alba (batch number: 18061201, source: Anhui China) and Glycyrrhizae Radix et Rhizoma Praeparata Cum Melle (batch number: 180518; source: Neimenggu China), which were authenticated by Professor Jingming Jia (Department of TCM, Shenyang Pharmaceutical University, Shenyang, China), were purchased from Guoda pharmacy (Shenyang, China). The primary source of reference compounds (purity $>$ 98\%), including benzoyl paeoniflorin, albiflorin, ononin, and glycyrrhizic acid, was Shanghai Yuanye Bio-Technology Co., Ltd 
(Shanghai, China), while gallic acid, liquiritin, paeoniflorin, and liquiritin apioside were obtained from the National Institute for the Control of Pharmaceutical and Biological Products (Beijing, China). Moreover, acetonitrile of HPLC grade and formic acid of LC-MS grade were obtained from Fisher Scientific (Fair Lawn, NJ, USA); purified water was then purchased from Wahaha (Hangzhou, China).

\subsection{Preparation of SGD for analysis}

As per SGD's original composition, two constituting herbs, Paeoniae Radix Alba (250 g) and Glycyrrhizae Radix et Rhizoma Praeparata (250 g), were mixed and macerated in purified water (5 L) for $0.5 \mathrm{~h}$, then boiled at $100{ }^{\circ} \mathrm{C}$ for $1.5 \mathrm{~h}$, and then the extracted solution was filtered through five layer gauzes. The residue was decocted twice with boiling water $(1: 8, \mathrm{v} / \mathrm{v})$ for $1 \mathrm{~h}$ each and the extracted solution was filtered using five layer gauzes. These three extractions were then combined and dried using lyophilization. Before analysis, dried powder $(0.5 \mathrm{~g})$ was dissolved in water (10 $\mathrm{mL}$ ), and then vortexed for $1 \mathrm{~min}$ for complete dissolution.

\subsection{Instrument and analytical conditions}

Chromatographic analysis was performed using an Agilent 1260 UHPLC system (USA) using a universal $\mathrm{XB} \mathrm{C}_{18}$ column $(150 \mathrm{~mm} \times$ $2.1 \mathrm{~mm}, 1.8 \mu \mathrm{m}$; Kromat, USA) at the column temperature of $35^{\circ} \mathrm{C}$. The mobile phase comprised $0.1 \%$ formic acid (A) and acetonitrile (B), and the gradient elution program was carried out for chromatographic separation as follows: $2-10 \%$ (B) from 0 to $12 \mathrm{~min}$, $10-25 \%$ (B) from 12 to $32 \mathrm{~min}, 25-62 \%$ (B) from 32 to $52 \mathrm{~min}$, and $62-65 \%$ (B) from 52 to $55 \mathrm{~min}$. The flow rate was $0.20 \mathrm{~mL} \mathrm{~min}{ }^{-1}$, and the injection volume was $2 \mu \mathrm{L}$.
Mass spectra analysis was conducted on a Bruker Solarix 7.0 T FT-ICR-MS system (Bruker, Germany) and a Bruker Compass-Hystar workstation (Bruker, Germany) using both positive and negative electrospray ionization (ESI) modes, followed by optimized conditions: nebulizer gas pressure of 4.0 bar; dry gas flow rate of 8 $\mathrm{L} \min ^{-1}$; dry gas temperature of $200{ }^{\circ} \mathrm{C}$; ion accumulation time of $0.15 \mathrm{~s}$; time of flight of $0.6 \mathrm{~ms}$; capillary voltage of $4.5 \mathrm{kV}$; and endplate offset of $500 \mathrm{~V}$. The recording of the full-scan mass spectrum data was performed between $\mathrm{m} / \mathrm{z} 100$ and 3000. In respect to the auto MS/MS mode, the selection of both MS/MS boost and MS/ MS isolation was made; moreover, the range of collision power was maintained between 10 and $30 \mathrm{eV}$ for MS/MS experimentations.

\section{Results and discussion}

Fig. 1 shows the base peak ion chromatograms (BPC) of SGD and the reference compounds. The extracted ion chromatograms (EIC) for each molecular weight, which are shown in the ESI (Fig. S1 and S2), $\uparrow$ were correspondingly obtained for detecting the associated compound. Among the identified compounds, the accurate identification of eight compounds was performed by comparing the retention time $\left(t_{\mathrm{R}}\right)$ and the MS/MS data associated with the reference compounds in the positive ion mode. The other compounds were determined by their retention times, as well as the molecular weight and the MS/MS fragments. Bruker workstation was used for computing the molecular formulas of the compounds by comparing the known molecular weights with the measured molecular weights, followed by limiting the acceptable error values to $<3.0 \mathrm{ppm}$. Using $\mathrm{MS} / \mathrm{MS}$ data, additional speculations of the layouts of the compounds were conducted. In aggregate, we reported 73 compounds and their

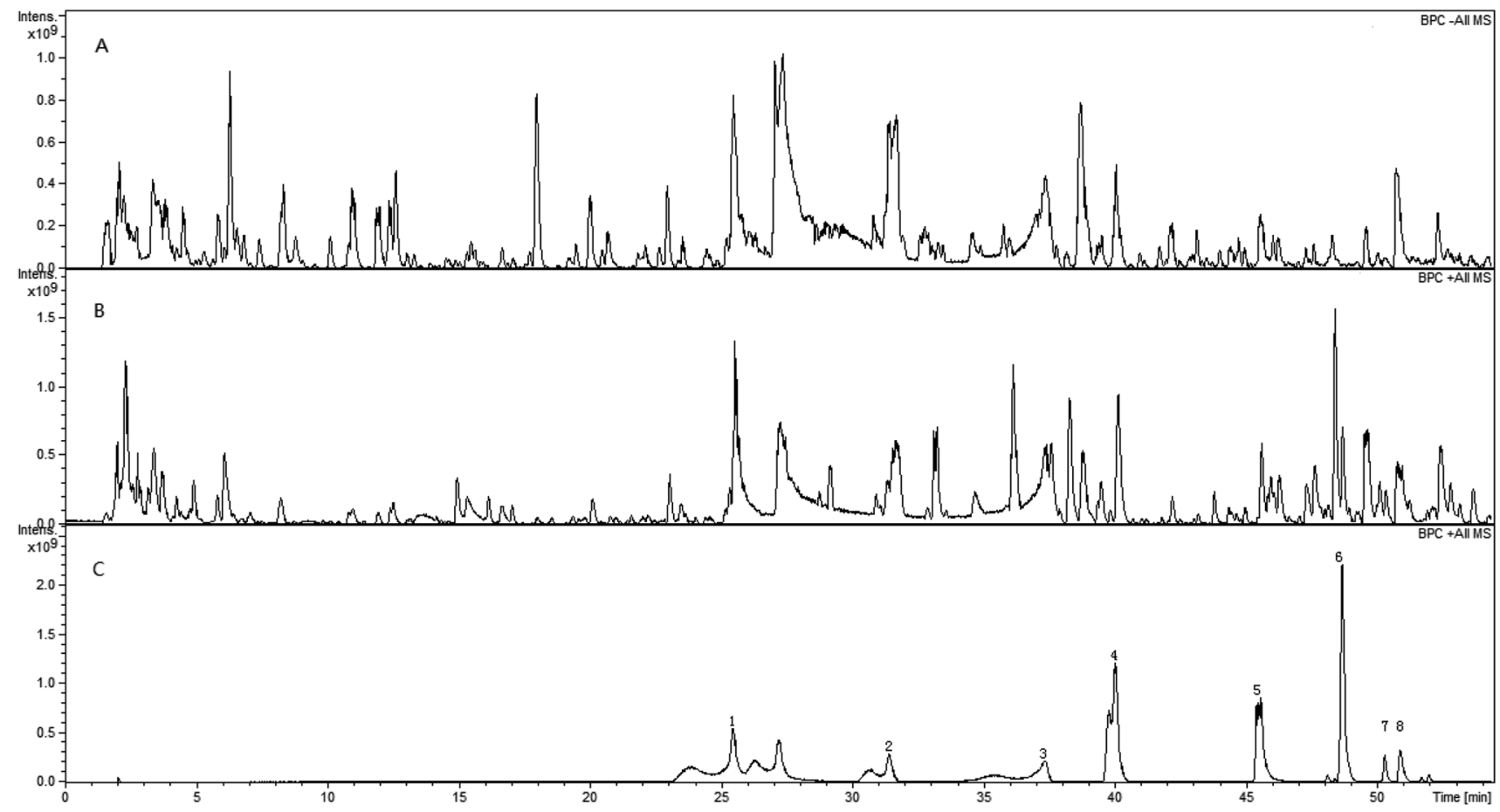

Fig. 1 The base peak ion chromatograms (BPC) of SGD in both positive (A) and negative (B) ion modes and the corresponding compounds (C). 
layouts are presented in Fig. S3 and S4. $\dagger$ Fig. S5 $\dagger$ shows the presentation of MS/MS spectra of the typical compounds while displaying their possible fragmentation pathways in Fig. 2. The inferences of each ingredient were carried out with the help of the molecular formulas and fragmentation pathways, followed by additional confirmation with reference to the previous literatures. ${ }^{8-16}$ Table 1 lists the retention time, formula, molecular weight, calculated $m / z$, detected $m / z$, error value and MS/MS data

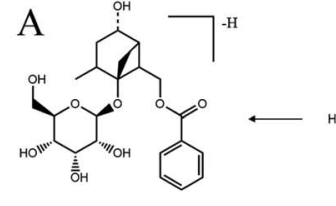

$\mathrm{m} / \mathrm{z} 435.1655$

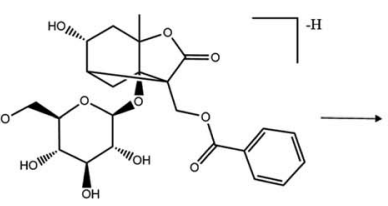

m/z 479.15587<smiles>O=C(O)c1ccccc1</smiles>

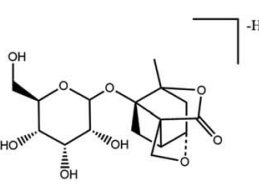

$\mathrm{m} / \mathrm{z} 357.11856$

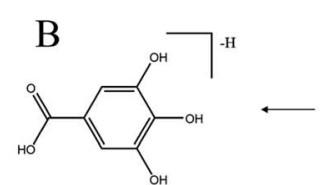

$\mathrm{m} / \mathrm{z} 169.01370$

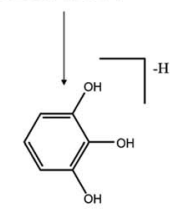

m/z 125.02387

$\mathrm{m} / \mathrm{z} 121.02895$<smiles>CC[C@H]1OC(OC(=O)c2cc(O)c(O)c(O)c2)[C@H](O)[C@@H](O)[C@@H]1OC</smiles>

$\mathrm{m} / \mathrm{z} 331.06707$

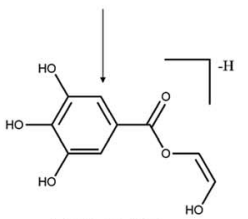

$\mathrm{m} / \mathrm{z} 211.02426$

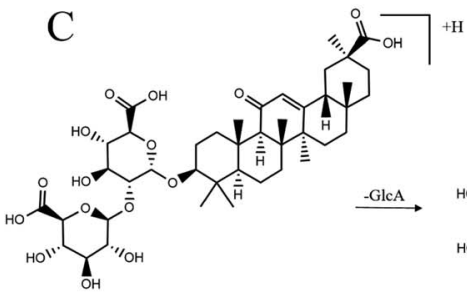

$\mathrm{m} / \mathrm{z} 823.44106$

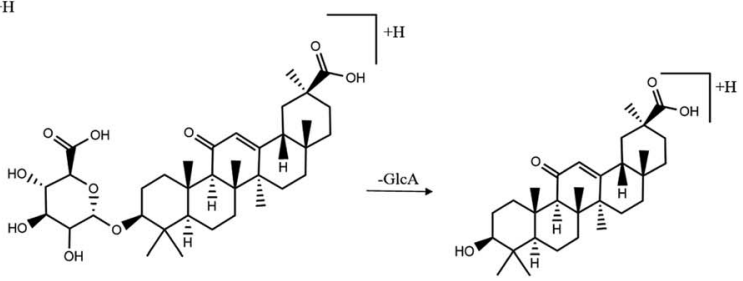

m/z 647.37952

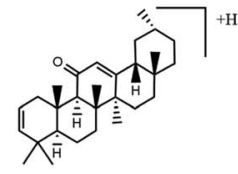

$\mathrm{m} / \mathrm{z} 407.33922$

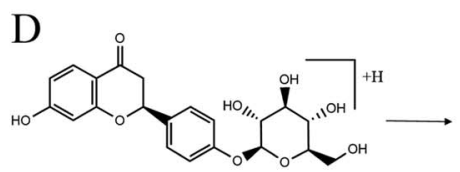

$\mathrm{m} / \mathrm{z} 417.11856$

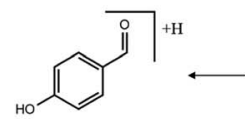

$\mathrm{m} / \mathrm{z} 119.03231$

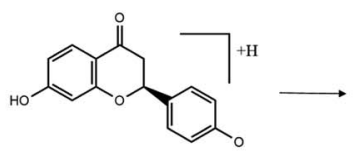

$\mathrm{m} / \mathrm{z} 255.06573$

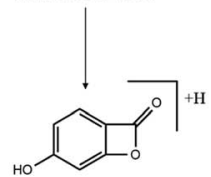

$\mathrm{m} / \mathrm{z} 135.00822$

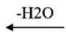

$\mathrm{m} / \mathrm{z} 471.34743$

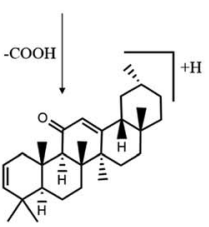

$\mathrm{m} / \mathrm{z} 425.35761$<smiles>CC[CH]CC</smiles>

$\mathrm{m} / \mathrm{z} 153.05070$

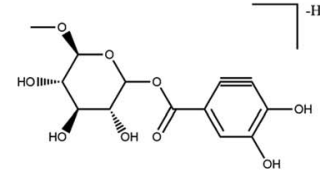

$\mathrm{m} / \mathrm{z} 313.05596$

Fig. 2 The possible fragmentation pathways of the typical compounds. (A) Albiflorin, (B) glucogallin, (C) glycyrrhizic acid, (D) liquiritin. 
Table 1 UHPLC-FT-ICR-MS analysis of Shaoyao Gancao detection ${ }^{a}$

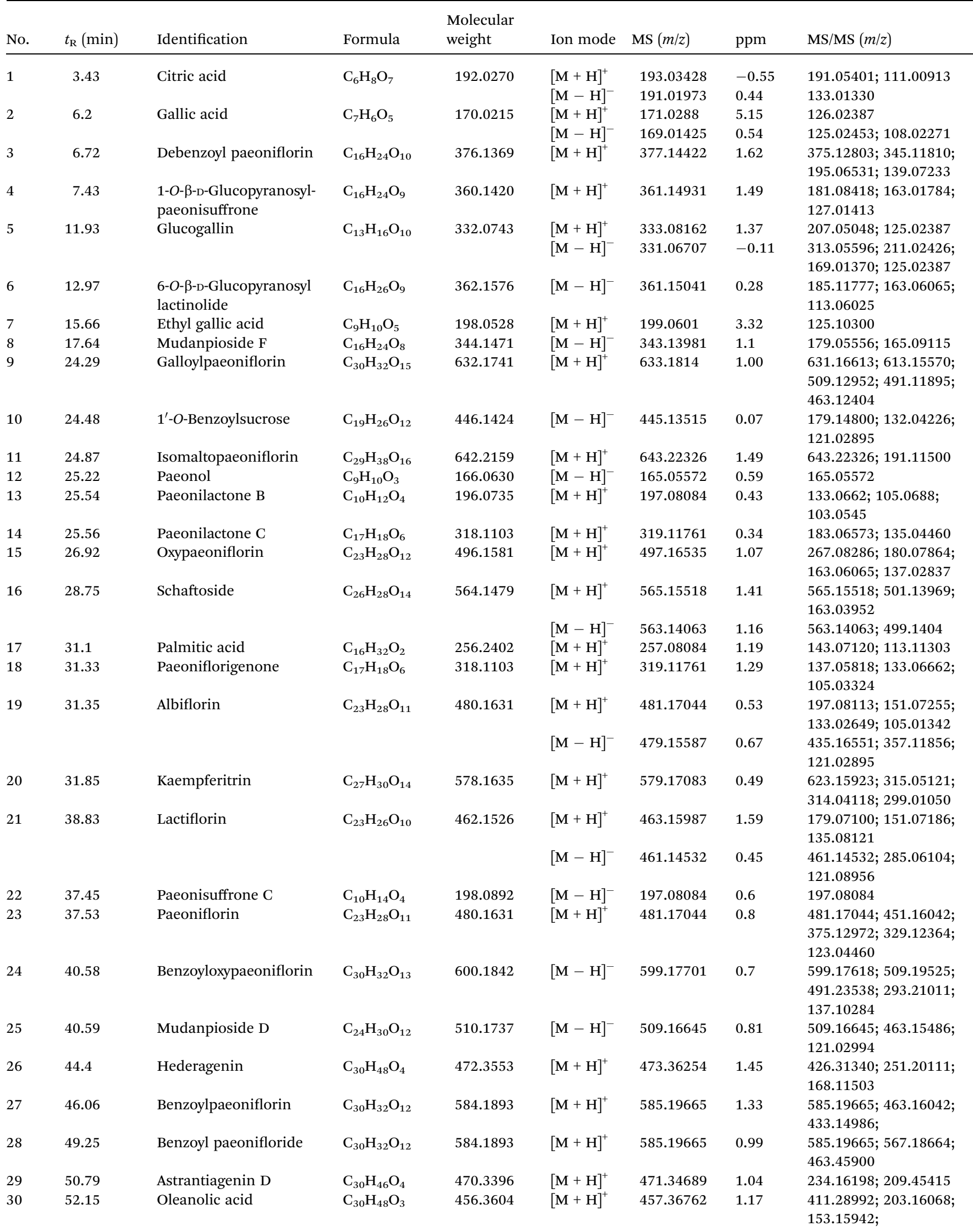


Table 1 (Contd.)

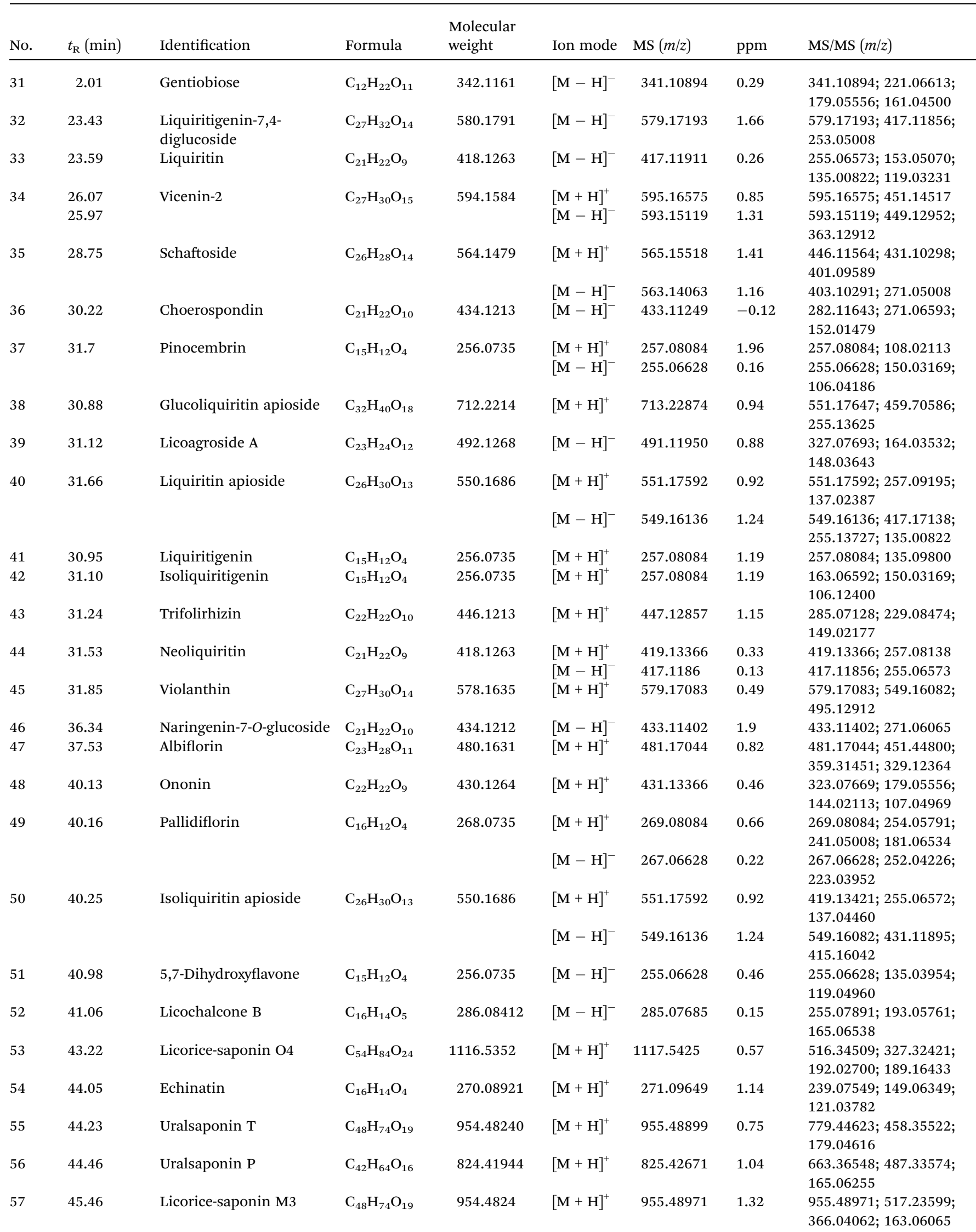


Table 1 (Contd.)

\begin{tabular}{|c|c|c|c|c|c|c|c|c|}
\hline No. & $t_{\mathrm{R}}(\min )$ & Identification & Formula & $\begin{array}{l}\text { Molecular } \\
\text { weight }\end{array}$ & Ion mode & $\operatorname{MS}(m / z)$ & ppm & MS/MS $(m / z)$ \\
\hline \multirow[t]{2}{*}{58} & \multirow[t]{2}{*}{45.84} & \multirow[t]{2}{*}{ Uralsaponin F } & \multirow[t]{2}{*}{$\mathrm{C}_{44} \mathrm{H}_{64} \mathrm{O}_{19}$} & \multirow[t]{2}{*}{896.4041} & {$[\mathrm{M}+\mathrm{H}]^{+}$} & 897.41146 & 0.7 & $\begin{array}{l}721.14563 ; 545.33269 ; \\
527.88076 ; 467.33254 ; \\
421.11257 ; 497.88210 ; \\
375.33245\end{array}$ \\
\hline & & & & & {$[\mathrm{M}-\mathrm{H}]^{-}$} & 895.3969 & 1.81 & $\begin{array}{l}\text { 719.36098; 543.11527; } \\
\text { 525.35432; 465.88908; } \\
\text { 419.44671; 495.54490; } \\
373.32157\end{array}$ \\
\hline 59 & 47.3 & 22-Acetoxyl-glycyrrhizin & $\mathrm{C}_{44} \mathrm{H}_{64} \mathrm{O}_{18}$ & 880.4092 & {$[\mathrm{M}+\mathrm{H}]^{+}$} & 881.4165 & 1.53 & $\begin{array}{l}705.13564 ; 529.11253 \\
518.00490 ; 451.33235 \\
405.44267\end{array}$ \\
\hline 60 & 47.6 & Licorice-saponin G2 & $\mathrm{C}_{42} \mathrm{H}_{62} \mathrm{O}_{17}$ & 838.3986 & {$[\mathrm{M}+\mathrm{H}]^{+}$} & 839.40598 & 0.57 & $\begin{array}{l}\text { 839.40598; 663.35370; } \\
487.37913\end{array}$ \\
\hline 61 & 48.42 & Licorice-saponin A3 & $\mathrm{C}_{48} \mathrm{H}_{72} \mathrm{O}_{21}$ & 984.4565 & {$[\mathrm{M}-\mathrm{H}]^{-}$} & 983.44933 & 0.3 & $\begin{array}{l}\text { 983.44933; 821.57765; } \\
645.33542 ; 351.11676\end{array}$ \\
\hline 62 & 48.49 & Uralsaponin $\mathrm{N}$ & $\mathrm{C}_{42} \mathrm{H}_{62} \mathrm{O}_{17}$ & 838.3987 & {$[\mathrm{M}+\mathrm{H}]^{+}$} & 839.40598 & 0.57 & $\begin{array}{l}663.37644 ; 487.32988 ; \\
179.05516\end{array}$ \\
\hline 63 & 48.91 & Licorice-saponin B2 & $\mathrm{C}_{42} \mathrm{H}_{64} \mathrm{O}_{15}$ & 808.4244 & {$[\mathrm{M}+\mathrm{H}]^{+}$} & 809.43180 & 1.13 & $\begin{array}{l}\text { 809.43180; 633.40026; } \\
439.39439\end{array}$ \\
\hline 64 & 49.28 & Formononetin & $\mathrm{C}_{16} \mathrm{H}_{12} \mathrm{O}_{4}$ & 268.0735 & {$[\mathrm{M}-\mathrm{H}]^{-}$} & 267.06628 & 0.54 & $\begin{array}{l}267.06628 ; 252.04226 ; \\
195.04460\end{array}$ \\
\hline \multirow[t]{2}{*}{65} & \multirow[t]{2}{*}{50.14} & \multirow[t]{2}{*}{$\begin{array}{l}22-\beta- \\
\text { Acetoxylglyrrhaldehyde }\end{array}$} & \multirow[t]{2}{*}{$\mathrm{C}_{44} \mathrm{H}_{64} \mathrm{O}_{17}$} & \multirow[t]{2}{*}{864.4142} & {$[\mathrm{M}+\mathrm{H}]^{+}$} & 865.42163 & -0.33 & $\begin{array}{l}\text { 689.37723; 513.34358; } \\
179.04966\end{array}$ \\
\hline & & & & & {$[\mathrm{M}-\mathrm{H}]^{-}$} & 863.40707 & 2.76 & $\begin{array}{l}\text { 481.33178; 353.07200; } \\
193.03483\end{array}$ \\
\hline 70 & 53.16 & Licorice-saponin $\mathrm{H} 2$ & $\mathrm{C}_{42} \mathrm{H}_{62} \mathrm{O}_{16}$ & 822.4037 & {$[\mathrm{M}+\mathrm{H}]^{+}$} & 823.41106 & 1.08 & $\begin{array}{l}\text { 823.41106; 647.37952; } \\
471.34743\end{array}$ \\
\hline \multirow[t]{2}{*}{71} & \multirow[t]{2}{*}{54.23} & \multirow[t]{2}{*}{ Licorice-saponin J2 } & $\mathrm{C}_{42} \mathrm{H}_{64} \mathrm{O}_{16}$ & 824.4194 & {$[\mathrm{M}+\mathrm{H}]^{+}$} & 825.42671 & 1.53 & $\begin{array}{l}\text { 825.42671; 649.39517; } \\
455.40456\end{array}$ \\
\hline & & & & & {$[\mathrm{M}-\mathrm{H}]^{-}$} & 823.41216 & 0.59 & $\begin{array}{l}\text { 823.41216; 647.37952; } \\
193.03483\end{array}$ \\
\hline 72 & 53.65 & Uralsaponin C & $\mathrm{C}_{42} \mathrm{H}_{64} \mathrm{O}_{16}$ & 824.4194 & {$[\mathrm{M}+\mathrm{H}]^{+}$} & 825.42671 & 1.53 & $\begin{array}{l}\text { 649.39517; 473.36309; } \\
455.35252 ; 437.34196\end{array}$ \\
\hline 73 & 53.96 & Glycycoumarin & $\mathrm{C}_{21} \mathrm{H}_{20} \mathrm{O}_{6}$ & 368.1259 & {$[\mathrm{M}-\mathrm{H}]^{-}$} & 367.11871 & 0.3 & $\begin{array}{l}367.11817 ; 296.27800 \\
369.13811 ; 313.07121 ; \\
285.07630\end{array}$ \\
\hline
\end{tabular}

${ }^{a}$ Ps: 1-30 from Paeoniae Radix Alba; 31-73 from Glycyrrhizae Radix et Rhizoma Praeparata.

of ingredients. A concrete illustration of the ingredients' characterization was performed as hereunder.

\subsection{Characterization of the constituents in Paeoniae Radix Alba}

Monoterpenes and several phenols were the primary active ingredients in Paeoniae Radix Alba with majority of them being monoterpenes. In this study, a tentative characterization of 30 compounds of Paeoniae Radix Alba in SGD was performed, followed by the identification of four of them. Peaks 1, 2, 3 and 6 in Fig. 1C can be attributed to gallic acid, albiflorin, paeoniflorin, and benzoyl paeoniflorin, respectively. Albiflorin was used as an illustration for demonstrating the fragmentation pathways of monoterpenes in Paeoniae Radix Alba. In the negative mode, the ion at $m / z 479.15587$ was inferred to be the adduct ion $\left([\mathrm{M}-\mathrm{H}]^{-}\right)$, followed by the calculation of the 
formula as $\mathrm{C}_{23} \mathrm{H}_{28} \mathrm{O}_{11}$. In the MS/MS spectrum, the key fragment ions found were at $\mathrm{m} / \mathrm{z}$ 435.16551, 357.11856, and 121.02895, which suggested the loss of $\mathrm{CO}_{2}(44 \mathrm{Da}), \mathrm{C}_{7} \mathrm{H}_{5} \mathrm{O}_{2}$ (122 Da) and $\mathrm{C}_{16} \mathrm{H}_{22} \mathrm{O}_{9}(358 \mathrm{Da})$ from the precursor ion, respectively. Glucogallin was selected as an illustration for demonstrating the fragmentation pathways of phenol. In respect to the negative mode, the ion at $\mathrm{m} / \mathrm{z} 331.06707$ was deducted to be the adduct ion $\left([\mathrm{M}-\mathrm{H}]^{-}\right)$and the calculated formula was $\mathrm{C}_{13} \mathrm{H}_{16} \mathrm{O}_{10}$. The important fragment ions found in the MS/MS spectrum were at $\mathrm{m} / \mathrm{z}$ 313.05596, 211.02426, 169.01370 and 125.02387. The ion at $\mathrm{m} / \mathrm{z} 313.05596$ can be attributed to the loss of $\mathrm{OH}(17 \mathrm{Da})$ from the precursor ion, whereas the ion at $m / z 211.02426$ can be attributed to the loss of $\mathrm{C}_{4} \mathrm{H}_{8} \mathrm{O}_{4}(120 \mathrm{Da})$ from the precursor ion. The ions at $\mathrm{m} / \mathrm{z}$ 169.01370 and 125.02387 represented $\mathrm{C}_{7} \mathrm{H}_{6} \mathrm{O}_{5}$ and $\mathrm{C}_{6} \mathrm{H}_{6} \mathrm{O}_{3}$, respectively, and the characterization of other compounds in Paeoniae Radix Alba was performed based on fragmentation patterns and related literature..$^{\mathbf{1 0 , 1 2 , 1 3}}$

\subsection{Characterization of constituents in Glycyrrhizae Radix et Rhizoma Praeparata Cum Melle}

Triterpene saponins and flavonoids were the primary active constituents in Glycyrrhizae Radix et Rhizoma Praeparata Cum Melle. ${ }^{14}$ In this research, tentative characterization of 43 ingredients of Glycyrrhizae Radix et Rhizoma Praeparata Cum Melle in SGD was performed, followed by the precise identification of four among them. Peaks 4, 5, 7 and 8 in Fig. 1C represented liquiritin, ononin, isoliquiritigenin, and glycyrrhizic acid, respectively. Glycyrrhizic acid was used as a common triterpene saponins composition of Glycyrrhizae Radix et Rhizoma Praeparata Cum Melle as an illustration for demonstrating the fragmentation pathways. In the positive mode, the ion at $\mathrm{m} / \mathrm{z}$ 823.44106 was inferred to be the adduct ion $\left([\mathrm{M}+\mathrm{H}]^{+}\right)$, followed by the calculation of the formula as $\mathrm{C}_{42} \mathrm{H}_{62} \mathrm{O}_{16}$. The key fragment ions found in the MS/MS spectrum were at $m / z$ 647.37952, $471.34743,425.35761$ and 407.33922 . The ion at $m / z 647.37952$ suggested the loss of $\mathrm{C}_{6} \mathrm{H}_{8} \mathrm{O}_{6}(176 \mathrm{Da})$ from the precursor ion, that at $m / z 471.34743$ revealed the loss of $\mathrm{C}_{6} \mathrm{H}_{8} \mathrm{O}_{6}(176 \mathrm{Da})$ from the $\mathrm{m} / \mathrm{z} 647.37952$, that at $\mathrm{m} / \mathrm{z} 425.35761$ suggested the loss of $\mathrm{CHO}_{2}$ (46 Da) from the $\mathrm{m} / \mathrm{z} 471.34743$, and that at $\mathrm{m} / \mathrm{z} 407.33922$ revealed the loss of $\mathrm{H}_{2} \mathrm{O}(18 \mathrm{Da})$ from the $m / z$ 425.35761. Liquiritin was used as an example for demonstrating the fragmentation pathways of flavonoids in Glycyrrhizae Radix et Rhizoma Praeparata Cum Melle. In respect to the negative mode, the ion at $m / z 417.11856$ was confirmed to be the adduct ion $\left([\mathrm{M}-\mathrm{H}]^{-}\right)$, followed by the calculation of the formula as $\mathrm{C}_{21} \mathrm{H}_{22} \mathrm{O}_{9}$. The key fragment ions found in the MS/MS spectrum were at $\mathrm{m} / \mathrm{z} 255.06573,153.05070,135.00822$ and 119.03231 . The ion at $m / z 255.06573$ denoted the loss of $\mathrm{C}_{6} \mathrm{H}_{11} \mathrm{O}_{5}(178 \mathrm{Da})$ from the precursor ion; that at $\mathrm{m} / z 153.05070$ denoted the loss of $\mathrm{C}_{7} \mathrm{H}_{3} \mathrm{O}(102 \mathrm{Da})$ from the $\mathrm{m} / z 255.06573$; that at $\mathrm{m} / z 135.00822$ denoted the loss of $\mathrm{C}_{8} \mathrm{H}_{7} \mathrm{O}(120 \mathrm{Da})$ from the $\mathrm{m} / \mathrm{z} 255.06573$; and that at $\mathrm{m} / \mathrm{z} 119.03231$ denoted the loss of $\mathrm{O}(16 \mathrm{Da})$ from the $\mathrm{m} / \mathrm{z}$ 135.00822. Characterization of the other ingredients in Glycyrrhizae Radix et Rhizoma was performed based on the fragmentation patterns and related literature. ${ }^{\mathbf{1 4 , 1 6}}$

SGD is a classical formula of traditional Chinese medicine that is extensively used in the clinic due to its anti-inflammatory, immunoregulatory, analgesic, antidepression, hepatoprotective and neuroprotective effects. ${ }^{12}$ Moreover, there is a wealth of study on the pharmacological effects of certain active components in the Paeoniae Radix Alba and Glycyrrhizae Radix et Rhizoma Praeparata Cum Melle. This study revealed that monoterpenes and several phenols (in Paeoniae Radix Alba) and the triterpene saponins and flavonoids (in Glycyrrhizae Radix et Rhizoma Praeparata Cum Melle) constituted the key ingredients in SGD. Some of these chemical components have been reported to be the active ingredients in SGD. ${ }^{\mathbf{8 , 1 0 , 1 3 , 1 7 , 1 8}}$ For example, paeoniflorin was reported to have anti-inflammatory, hepatoprotective and neuroprotective effects. ${ }^{19,20}$ Albiflorin was shown to be both antiinflammatory and antioxidant. ${ }^{9,21}$ Polyphenol was reported to play a role in antioxidant and antiviral activity. Pentagalloylglucose was shown to have anti-inflammatory, anti-allergic, antitumor, antiviral and antibacterial effects. Paeonol was reported to have anti-inflammatory, antitumor, anti-allergic, antioxidant activities, along with cardiovascular and neuroprotective effects. $^{22}$ Liquiritin had antidepressive and neuroprotective effects. $^{23,24}$ Liquiritigenin had been reported to exhibit antiinflammatory effect. ${ }^{25}$ Saponins from liquorice demonstrated anti-inflammatory, antiarrhythmia and hepatoprotective effects. $^{26,27}$ To better understand the major functional compounds and the mechanism of SGD, additional research is required. This study provides a good basis for identifying the prototype components and metabolites in SGD, which can better illustrate its medicinal value.

\section{Conclusions}

A rapid method was performed to systematically characterize 73 chemical constituents of SGD in total with the help of UHPLCFT-ICR-MS. Experimental results reveal that phenols and monoterpenes (in Paeoniae Radix Alba), triterpene saponins and flavonoids (in Glycyrrhizae Radix et Rhizoma Praeparata Cum Melle) are the primary components in SGD. Moreover, it provides more information about the compounds in SGD than the previous literature. Therefore, the results of this study can be used to evaluate the quality of SGD and provide a basis for subsequent in vivo studies of SGD. Furthermore, this work provides a method for rapid identification of other TCMs. However, additional studies are required to overcome the limitation of identifying only known compounds using this method.

\section{Abbreviations}

BPC

EIC

SGD

TCM
Base peak ion chromatograms Extracted ion chromatograms Shaoyao Gancao decoction Traditional Chinese medicine 
UHPLC-FT-ICR- Ultra high-performance liquid MS/MS chromatography coupled with Fourier transform ion cyclotron resonance mass spectrometry

\section{Conflicts of interest}

The authors declare that there are no conflicts of interest.

\section{Acknowledgements}

This work was supported by the National Natural Science Foundation of China (NSFC: 81973284). This work was supported by Natural Science Foundation of Liaoning Province 2018 (Grant No. 20180551259).

\section{References}

1 P. Dong, L. Zhang, L. Zhan and Y. Liu, J. Sep. Sci., 2016, 39, 595-602.

2 Y. Jiang, R. Liu, J. Chen, M. Liu, M. Liu, B. Liu, L. Yi and S. Liu, J. Chromatogr. A, 2019, 1600, 197-208.

3 Z. J. Zhang, Treatise on Febrile Diseases (Shang Han Lun), The Eastern Han Dynasty.

4 C.-H. Xu, P. Wang, Y. Wang, Y. Yang, D.-H. Li, H.-F. Li, S.-Q. Sun and X.-Z. Wu, J. Ethnopharmacol., 2013, 149, 443452.

5 Q. Yin, P. Wang, A. Zhang, H. Sun, X. Wu and X. Wang, J. Sep. Sci., 2013, 36, 1238-1246.

6 Y. Wang, F. Han, A. Song, M. Wang, M. Zhao and C. Zhao, J. Sep. Sci., 2016, 39, 4325-4334.

7 Z. Guan, M. Wang, Y. Cai, H. Yang, M. Zhao and C. Zhao, J. Chromatogr. B: Anal. Technol. Biomed. Life Sci., 2018, 1086, 11-22.

8 Z. Li, H. Gao, J. Li and Y. Zhang, J. Sep. Sci., 2017, 40, 25582564.

9 Y. Yan, C.-Z. Chai, D.-W. Wang, J. Wu, H.-H. Xiao, L.-X. Huo, D.-N. Zhu and B.-Y. Yu, J. Pharm. Biomed. Anal., 2014, 95, 7684.

10 B. Yan, M. Shen, J. Fang, D. Wei and L. Qin, J. Pharm. Biomed. Anal., 2018, 160, 276-288.
11 K. Pei, Y. Duan, H. Cai, S. Tu, F. Qiao, X. Song, X. Liu, G. Cao, K. Fan and B. Cai, Anal. Methods, 2015, 7, 9442-9451.

12 S.-L. Li, J.-Z. Song, F. F. K. Choi, C.-F. Qiao, Y. Zhou, Q.-B. Han and H.-X. Xu, J. Pharm. Biomed. Anal., 2009, 49, 253-266.

13 L. Shan, N. Yang, Y. Zhao, X. Sheng, S. Yang and Y. Li, J. Sep. Sci., 2018, 41, 3791-3805.

14 Y. Cui, T. Liu, Y. Zhang, R. Wang, X. Liu, Q. Zhang, P. Yu, Y. Zhao and Z. Yu, J. Pharm. Biomed. Anal., 2018, 159, 318325.

15 Y. Xu, H. Cai, G. Cao, Y. Duan, K. Pei, S. Tu, J. Zhou, L. Xie, D. Sun, J. Zhao, J. Liu, X. Wang and L. Shen, J. Chromatogr. B: Anal. Technol. Biomed. Life Sci., 2018, 1083, 110-123.

16 C. Schmid, C. Dawid, V. Peters and T. Hofmann, J. Nat. Prod., 2018, 81, 1734-1744.

17 N. Y. Tang, C. H. Liu, C. T. Hsieh and C. L. Hsieh, Am. J. Chin. Med., 2010, 38, 51-64.

18 C. Feng, M. Liu, X. W. Shi, W. Yang, D. Z. Kong, K. P. Duan and Q. Wang, J. Ethnopharmacol., 2010, 130, 407-413.

19 X. Li, J. Shen, Z. Zhong, J. Peng, H. Wen, J. Li, Q. Luo and W. Wei, Parasitology, 2010, 137, 1213-1225.

20 A. Manayi, S. Omidpanah, D. Barreca, S. Ficarra, M. Daglia, S. F. Nabavi and S. M. Nabavi, Phytochem. Rev., 2017, 16, 1173-1181.

21 K. S. Suh, E. M. Choi, Y. S. Lee and Y. S. Kim, Fitoterapia, 2013, 89, 33-41.

22 S. Parker, B. May, C. Zhang, A. L. Zhang, C. J. Lu and C. C. Xue, Phytother Res., 2016, 30, 1445-1473.

23 W. Wang, X. Hu, Z. Zhao, P. Liu, Y. C. Hu, J. P. Zhou, D. F. Zhou, Z. B. Wang, D. Guo and H. Z. Guo, Prog. NeuroPsychopharmacol. Biol. Psychiatry, 2008, 32, 1179-1184.

24 L. S. Teng, Q. F. Meng, J. H. Lu, J. Xie and Z. Z. Wang, Mol. Med. Rep., 2014, 10, 818-824.

25 J. E. Mersereau, N. Levy, R. E. Staub, S. Baggett, T. Zogric, S. Chow, W. A. Ricke, M. Tagliaferri, I. Cohen and L. F. Bjeldanes, Mol. Cell. Endocrinol., 2008, 283, 49-57.

26 H. Hosseinzadeh and M. Nassiri-Asl, Phytother Res., 2015, 29, 1868-1886.

27 B. Liang, X. L. Guo, J. Jin, Y. C. Ma and Z. Q. Feng, World J. Gastroenterol., 2015, 21, 5271-5280. 